\title{
Movimentos Feministas
}

Naiara Andreoli Bittencourt ${ }^{1}$

\section{AS "ONDAS" DOS MOVIMENTOS FEMINISTAS E O EUROCENTRISMO DA HISTÓRIA}

"Em nenhum país do mundo pode-se falar em feminismo no singular". Saffioti (1986, p. 105), uma das principais feministas expoentes do marxismo brasileiro, alerta para a multiplicidade de organizações e posicionamentos teóricos dos movimentos feministas ao longo da história da organização de mulheres. Dessa forma, é falsa a afirmação de que há um histórico do movimento feminista, mas sim uma síntese hegemônica de determinado período que caracteriza o enfoque dos diversos movimentos feministas, em que cada um assume uma posição política demarcada e delineia determinada estratégia.

Assim, apesar de não haver um único posicionamento do movimento feminista, é possível identificar certos paradigmas ou ideologias predominantes que se revelam em reivindicações e pautas de determinada época (SAFFIOTI, 1986, p. 105). Por isso, este verbete iniciará com uma síntese histórica do movimento feminista hegemônico, principalmente com os recortes temporais e espaciais da Europa e Estados Unidos, para problematizar as grandes transformações e marcos do movimento, para posteriormente traçar as vicissitudes dos movimentos feministas nos países periféricos do capitalismo. Também

1 Mestranda em Direito pela UFPR, membro da coordenação do projeto de Projeto de Promotoras Legais Populares de Curitiba e Região, membro do NEFIL - Núcleo de Estudos Filosóficos do Programa de Pós-Graduação da UFPR. 
procurar-se-á situar seus principais nomes e suas principais reivindicações, simultaneamente com o ascenso e descenso dos movimentos sociais em geral nesses períodos e nas reais conquistas e avanços que foram obtidas pela luta das mulheres.

Identifica-se, portanto, pelo menos dois grandes marcos na história do movimento feminista (RODRIGUES, 2001) que culminam na heterogeneidade do movimento atual. Há autoras que se referem a três "ondas" expressivas de organização de mulheres, em que a terceira onda traria o momento atual do feminismo e sua representação e atuação como continuidades da segunda onda após a década de 1990.

Inicialmente deve-se frisar que as respostas das mulheres à opressão estrutural do patriarcado e à dominação masculina sempre ecoaram no silêncio da história e foram apagadas e esquecidas pela voz grave dos dominantes. Possíveis registros e representações das lutas das mulheres foram neutralizados, de forma que não é possível afirmar certamente sobre a existência de grupos organizados de mulheres que se opunham à desigualdade, apenas personalidades e ataques de forma individualizada, mascarando seu aspecto de gênero (SAFFIOTI, 1986, p. 105).

Por isso, as primeiras organizações feministas são datadas do final do século XVIII, com o advento da Revolução Francesa, que se estendem até as primeiras décadas do século $X X$ e caracterizam a primeira onda feminista, conhecida como "sufragista". Nesta fase há a solidificação de correntes políticas entre os movimentos, como: a liberal, a anarquista, a socialista e a conservadora (cristã) (RODRIGUES, 2001).

A primeira onda, impulsionada pelo paradigma do liberalismo, funda-se na ideologia burguesa e na busca por um conceito ampliado de cidadania (MATOS, 2010, p. 68), incluindo as mulheres, os homens negros e parte das camadas populares. Segundo Saffioti (1986, p. 107), a proposta fundamental era "ampliar o que se entende por democracia, tornando iguais perante a lei os crescentes contingentes humanos das sociedades competitivas. Nesta concepção, cabe reivindicar para as mulheres igualdade de direitos com relação aos homens no plano de jure".

As principais lutas concretas referem-se, portanto, a formação profissional e a representação política, reivindicando o acesso à educa- 
ção formal, ao trabalho remunerado e ao voto. Tal fase é caracterizada como ligada "ao interesse das mulheres brancas de classe média" por apresentar pautas generalizadas de igualdade formal inclusiva que em pouco ferem a estrutura patriarcal historicamente edificada. Mesmo assim, travam uma importância imensurável, ao ser um movimento extremamente massivo, sendo que milhares de mulheres ocuparam as ruas da Inglaterra e Estados Unidos, sofrendo graves represálias penais e sociais (PINTO, 2010). Ou seja, mesmo restringindo-se às conquistas "formais", o impacto na ordem patriarcal era inegável.

Há também inúmeros levantes feministas, principalmente dos partidos comunistas europeus e russo que travam o recorte classista e a necessidade de um rompimento brusco com a estrutura econômica capitalista e suas multifacetadas explorações, como é o caso de caso de Clara Zetkin, Alexandra Kollontai e Rosa Luxemburgo, oriundas da vertente marxista e Emma Goldman do anarquismo.

Entretanto, sempre que o movimento restringe-se a pautas isoladas, sem observar a estrutura de dominação e exploração que antecede a discriminação pontual, conquistados os direitos formais - civis e políticos -, a luta de massas está fadada a arrefecer. Isto é, as décadas de 1930 e 1940 revelam o descenso feminista, pois as mulheres poderiam votar e ser votadas, frequentar universidades e escolas e ingressar no mercado de trabalho: direitos adquiridos pelo período de grandes guerras mundiais e pelos postos vagos dos homens operários que foram impelidos aos campos de batalha. Marcam-se também as ideologias nazistas e fascistas deste período que culminavam num maior controle feminino e na tentativa de reforçar os papeis sociais como inerentes e naturais e marcaram o arrefecimento das mobilizações populares como um todo (ALVES; PITANGUY, 1985, p. 49-50).

Com o término das guerras mundiais houve a retomada masculina do mercado industrial e, visto que no capitalismo não existe pleno emprego e há necessidade da formação do exército de reserva, este novamente se torna essencialmente feminino. O papel estatal e midiático teve fundamental influência no retorno da mulher ao espaço doméstico e domesticado. As propagandas neste período exaltam a figura da 
dona-de-casa servil ao marido, do papel de esposa e mãe e do fomento à indústria de beleza e estética (ALVES; PITANGUY, 1985, p. 50).

Assim, diversas teóricas feministas começam a questionar o reforço de tais papeis culturais e sociais e procuram retomar certas conquistas atingidas pelo ingresso no mercado do trabalho, como: o espaço público (ainda que precarizado e desvalorizado); o ingresso nas universidades; e a conquista de democracia representativa, de forma a romper os entraves das reivindicações formais da primeira onda feminista.

O cenário mundial também é marcado por uma intensa efervescência, como o movimento hippie nos EUA, a Guerra do Vietnã, o maio de 1968 em Paris, o lançamento da pílula anticoncepcional e os levantes populares (PINTO, 2010), o que fomenta também o retorno das organizações políticas de mulheres.

A segunda onda, portanto, compreende o período entre as décadas de 1960 e 1980 num avanço de percepção e análise do movimento como um todo, incorporando diversas frentes de luta e denunciando o patriarcado como forma de expressão do poder político exercido através da dominação masculina e inferiorização das mulheres que ultrapassa o campo do privado, invade todos os espaços da sociedade e representa uma estrutura de poder baseada tanto na violência quanto na ideologia (SAFFIOTI, 2004, p. 53-58).

A partir de então, o próprio movimento feminista, também influenciado por outras organizações políticas e movimentos sociais, critica seu caráter burguês-liberal de outrora, fazendo recortes de classe e raça, relações de poder e transversalidade de opressões estruturais para além do gênero. Assim, elevam-se as vozes das mulheres negras e pobres subjulgadas dentro do movimento.

Inclusive, é nesse período em que se formulam as problematizações acerca das diferenças entre gênero, sexo e orientação sexual, desmitificando a naturalização de papeis sociais que seriam inerentes a homens ou mulheres. Ainda há a importante contribuição do questionamento da dicotomia artificial dos espaços públicos e privados, ressaltando que o "pessoal" ou o privado são espaços políticos e que devem ser desvelados. 
Neste segundo momento marcante dos movimentos feministas destacam-se várias autoras como Gloria Jean Watkins, Heleieth lara Saffioti, Joan Scott, Betty Friedan, Nancy Fraser, Juliet Mitchell, etc.

Contudo, o grande baque neoliberal das décadas de 1980 e 1990 alavancaram o poder do mercado globalizado transnacional, de flexibilizações trabalhistas e do descenso geral dos movimentos sociais que encontravam um panorama repressivo, ideológico e econômico completamente desfavorável aos impulsos populares. Com o movimento feminista não foi diferente e, a partir de então, há divergências teóricas fundamentais sobre a real existência e fundamentação de uma terceira onda do movimento, guiada por autoras e ativistas da segunda onda e impulsionada pela produção acadêmica e a reorganização dos movimentos combativos ou reivindicatórios para a institucionalidade ou para as universidades.

É chamada por diversos nomes que remetem à convergência teórica e política proclamada como o pós-modernismo, inclusive reafirmando-se como "pós-feminismo" ou "feminismo da diferença", criticando a segunda onda por seu suposto caráter monolítico, universal e generalizante, sem perceber as implicações individuais ou subjetivas das mulheres. Elabora, por isso, uma teoria fluída, particular e flexibilizada, rechaçando o estruturalismo e focando-se principalmente no micropoder e na micropolítica. Em geral, o pós-feminismo "têm por objetivo desconstruir/desestabilizar o gênero enquanto categoria fixa e imutável" (MACEDO, 2006).

Tais posicionamentos acabam por trazer uma agenda individual ou liberal, desligando as organizações coletivas como pressuposto da transformação política, e principalmente da transformação estrutural da sociedade patriarcal. Entretanto, diversas autoras, ainda que tragam o viés da instabilidade e multiplicidade da subjetividade, afirmam que o pós-feminismo não se trata de anti-feminismo ou "backlash", mas de reafirmação das lutas feministas já conquistadas através de um feminismo "plural", como uma recusa da hegemonia de um tipo de feminismo sobre outro (MACEDO, 2006). Neste aspecto, as autoras Susan Bordo, Elizabeth Grosz, Judith Butler e Donna Haraway destacam-se na produção intelectual, formulando novas categorias de aná- 
lise à dominação masculina na atualidade e propõem a resignificação dos gêneros numa perspectiva pós-identitária, como a Teoria Queer.

Em que pese as inúmeras contribuições da denominada terceira onda para o feminismo - tais como o questionamento do enclausuramento cerrado do conceito de gênero, da contestação expressiva à heteronormatividade, a construção dos corpos, o transfeminismo e a sexualidade - a expressão "pós-feminismo" e a ideologia apregoada a ela da negação de uma revolução estrutural permite a interpretação de que não há mais uma razão política do lutar coletivo feminista, vez que a igualdade formal estaria satisfeita e bastaria a mulher, individualmente, buscar a satisfação de sua liberdade plena, correntemente focada na sexualidade ou simplesmente no poder de consumo.

Neste panorama, alguns avanços fundamentais da segunda parecem olvidados, como a percepção dos recortes de classe e raça e o avanço do feminismo para além das mulheres brancas e de classe média, abandonando as relações estruturais imbricadas que o patriarcado e o machismo assumem com o racismo e com a exploração capitalista. Esquece-se que a libertação jamais ocorre de maneira individual e fechada, mas prescinde da organização e da superação de qualquer forma de violência e inferiorização de todas as mulheres e não apenas àquelas que "decidem" ou "querem" ser livres no plano estritamente pessoal.

\section{A CONSTRUÇÃO DOS FEMINISMOS NA AMÉRICA LATINA: BREVES ELEMENTOS}

Como afirmado anteriormente, a historicidade hegemônica feminista é somente um modo de ler e interpretar a construção do feminismo e das mulheres em âmbito global. A hegemonia das críticas feministas, em geral, limita-se à Europa e Estados Unidos e trazem uma concepção de "mulher" branca, ocidental e burguesa em suas análises, desconsiderando as especificidades das margens capitalistas, como a América Latina, a Ásia e a África em sua quase totalidade, onde há uma colonização imposta de tal modelo ocidental de poder de forma a 
possibilitar a exploração ainda mais intensa das trabalhadoras e ampliar o controle sobre seus corpos, sua sexualidade e sua organização política - os espaços públicos de poder.

Destarte, o feminismo latino-americano de modo algum pode equiparar-se ao feminismo eurocêntrico ou norte-americano, derivado de condições externas à realidade das colônias e dos países de capitalismo dependente. Deve-se pensar numa real descolonização do feminismo, para atingir as camadas populares de mulheres nas margens do sistema-mundo, reconhecendo as transversalidades de gênero, raça e classe. A centralidade das perspectivas de um feminismo descolonial, que parta de nuestra América, pretende concatenar uma estreita relação com o debate racial, da exterioridade das mulheres negras, indígenas e mestiças, questionando também uma colonização "embranquecedora" do próprio feminismo e das teorias críticas.

Desta forma, a grande questão a ser tratada na América Latina são os frutos de uma sociedade colonizada, escravocrata e dominada pelas potências europeias a fim de impulsionar o capitalismo mercantil. Neste processo, as mulheres indígenas, negras e mestiças protagonizaram o sofrimento da violência, dominação e exploração, constituindo a força motriz imposta da formação das nações que aqui se edificaram. Ademais, representaram as maiores composições da resistência feminina contra a opressão, ainda que tais práticas fossem abafadas pela "história dos vencedores".

O feminismo tradicional do século XX concentrou suas teorias a respeito de uma caracterização das mulheres como frágeis, débeis, reclusas no espaço privado e passivas. Entretanto, tais caracterizações excluem completamente o recorte de raça, vez que as mulheres "não brancas" eram consideradas seres "sem gênero", marcadas sexualmente como fêmeas, sem as características da feminilidade, passíveis de violações e perversões sexuais, essencialmente erotizadas e suficientemente fortes para empreender trabalhos forçados no espaço público e privado e a própria escravização (LUGONES, 2008).

Por isso, a imprescindibilidade de se considerar diversos fatores que implicam em um feminismo pouco equiparável aos países de capita- 
lismo central. Um desses fatores é a divisão sexual, social e internacional do trabalho, que conjugadas permitem uma maior intensidade do ritmo produtivo às mulheres; a menor remuneração; a ocupação em postos marginalizados ou subempregos; a separação das esferas pública e privada; legitima a dupla jornada de trabalho e delega às mulheres as funções que deveriam ser prestadas pelo Estado Social (creches, educação, cuidados, lavanderias, restaurantes) - especialmente no cenário neoliberal ainda vigente. Este diagnóstico ainda se amplia se verificadas as condições das mulheres negras e indígenas, ainda mais exteriores à totalidade posta.

O imperialismo político, bélico e econômico global dos países hegemônicos, além de atribuir a divisão do trabalho internacional e a exploração dos países do Sul, acentua as desigualdades e a dominação principalmente entre as mulheres, dividindo-as em consumidoras e produtoras, em que a possibilidade de libertação (ainda que na lógica de mercado, pois a discriminação e a opressão se manifestam de diversas formas) para algumas mulheres dos países centrais depende da superexploração das mulheres latinas, africanas e asiáticas, intensificando sua jornada, reduzindo seus direitos trabalhistas, sexuais e reprodutivos e criando mecanismos ideológicos que perpetuem a manutenção do patriarcado e da submissão feminina, não somente em uma lógica familiar, mas no âmbito dos Estados-Nações, das políticas governamentais e do mercado internacional.

Outro fator que deve ser considerado é o longo período ditatorial militar neste continente, marcado pelo alinhamento político às grandes potências hegemônicas imperialistas. No início dos anos 1960 as crises econômicas agravaram-se, e os diversos movimentos de transformação que surgiram em nações americanas foram atacados pelo interesse das burguesias nacionais com o respaldo norte-americano.

A ação do movimento feminista articulou-se em um contexto de ditaduras e integrou o processo de luta pela redemocratização, no qual o feminismo construiu relações com outros movimentos sociais, havendo uma interseção com uma visão socialista e classista, voltada às muIheres do meio popular. Entretanto, tais lutas dentro da esquerda ainda eram nascentes, vez que os partidos e movimentos sociais "mistos" por 
vezes não reconheciam a importância do feminismo, considerando-o liberal, da classe média ou da pequena burguesia (FARIA, 2005, p. 12).

Tudo isso determinou que na América Latina a formação de movimentos feministas em sua essência tenha sido tímida e incipiente, não representando de fato uma organização massiva e popular, sendo que os espaços feministas normalmente acabam sendo ocupados por mulheres organizadas em outros movimentos sociais e partidos políticos ou mesmo mulheres estudantes que se aproximam pelo debate acadêmico, hoje em voga nas universidades.

A principal trajetória de passagem do plano estritamente privado ao público na América Latina, como afirma Céli Regina Pinto (1992), é a inserção de mulheres e a criação de "departamentos femininos", ao que preferimos de chamar de grupos internos auto-organizados dentro dos próprios partidos ou movimentos sociais populares. Estes espaços possibilitam uma visibilidade política importantíssima para as mulheres: primeiro pela possibilidade de seu empoderamento para a disputa real política dentro e fora do partido, superando uma questão formal de vagas ou cotas; segundo pela sistematização e luta por pautas exclusivas das mulheres, normalmente inferiorizadas ou secundarizadas dentro das organizações mistas. Contudo, é importante destacar que a fragilidade ou imaturidade dos movimentos autônomos de mulheres leva a uma percepção secundária da luta feminista, sempre atrelada a outras organizações "maiores", representando, também, a força reduzida das movimentações feministas na América Latina.

\section{E HOJE? QUAL É O PANORAMA?}

Os movimentos feministas reafirmam sua pluralidade e multiplicidade. Percebe-se, com as diversas perspectivas da globalização e do neoliberalismo diferentes posicionamentos e organizações conforme a conjuntura dos países e sua localização geopolítica, em que inúmeros desafios se colocam como prioridade nas lutas das mulheres.

Nos países europeus e norte-americanos as principais pautas giram em torno da sexualidade feminina e da livre disposição do corpo 
pela própria mulher, assumindo total autonomia sobre suas decisões. Eclodem movimentos que lutam contra a sexualização excessiva dos corpos e de sua mercantilização, trazendo também o debate da culpabilização feminina em casos das diversas formas de violência contra a mulher, como é o caso da SlutWalk no Canadá, Marcha das Galdérias em Portugal e o Femen iniciado na Ucrânia.

Observa-se, entretanto, nos últimos anos uma nova politização dos movimentos feministas europeus, principalmente dos partidos de esquerda, quanto à flexibilização aos direitos trabalhistas frente à crise econômica mundial, em que se ampliam as desigualdades entre os sexos e as mulheres que já ocupavam os postos de trabalho mais precarizados tendem a sofrer mais com a retirada de serviços essenciais do Estado.

Importante situar, ainda de que forma superficial, a diferença de reivindicações das mulheres progressistas nos países asiáticos, principalmente nos de religião islâmica, as quais se situam nos primeiros passos de liberdade de expressão, deslocamento, disposição de atos civis, como o divórcio e a guarda dos filhos, a recusa aos casamentos arranjados e as relações sexuais forçadas com maridos, a exposição mínima do corpo, a educação formal e o ingresso nas universidades, a remuneração e reconhecimento no mercado de trabalho e principalmente o fim das mutilações genitais ou sexuais das mulheres e crianças, além das penas de apedrejamento e morte ao adultério, por exemplo.

No cenário latino-americano, como destrinchado em ponto anterior, há especificidades que não podem ser desconsideradas no enfrentamento dos movimentos feministas à ordem patriarcal, racista e capitalista dependente. É evidente, ainda, a predominância de feminismos extremamente colonizados, brancos, eurocêntricos e heteronormativos, que trazem como paradigma um "ideal" de mulher distante da realidade epistêmica do sul global, dos povos periféricos ou marginalizados.

A redemocratização na maioria dos países latino-americanos, já em tempos neoliberais, trouxe várias mudanças na agenda feminista e muitas vezes os setores dos movimentos feministas passaram a privilegiar a atuação no interior dos governos, exemplificado pela eclosão de ONGs e instituições voltadas à promoção de políticas públicas. 
Sem, obstante, travar grandes enfrentamentos nas ruas e movimentar massivamente as mulheres e questionar abruptamente as estruturas do Estado vigente.

Mesmo assim, várias iniciativas têm se edificado ao longo das duas últimas décadas que procuram tematizar as transversalidades de opressões e o reconhecimento das sujeitas protagonistas de sua transformação a partir de uma identidade comum, como é o caso no Brasil das mulheres negras (Rede de Mulheres Negras), lésbicas (Articulação Brasileira de Lésbicas - ABL), transexuais (transfeminismo), camponesas (Movimento de Mulheres Camponesas - MMC), da Marcha Mundial de Mulheres que debate a relação entre classe e Gênero, etc. Tais movimentos organizam-se principalmente em redes que se descentralizam nas regiões e focam principalmente na reivindicação de políticas públicas com os recortes específicos.

Deve-se lembrar também que em nosso país, a grande impulsão das organizações feministas num partido e de grandes quadros da militância de mulheres teve o auge na formação dos Partidos dos Trabalhadores, nas décadas de 80/90, o que trouxe um acúmulo considerável ao partido e ao recorte classista das reivindicações partidárias, transformando em alguma medida a questão "corporativa" em questão de interesse geral.

Contudo, com a chegada do partido no poder político, há uma alteração significativa no que concerne à institucionalização formal e a mudança das reivindicações com o enfoque na concretização de planos e programas de políticas públicas para mulheres, através das eleições em grande escala pelo partido nos postos legislativos e executivos do país. Os principais quadros feministas são absorvidos ao Estado e a tensão entre movimento e governo parece apaziguar-se com o não enfrentamento e a mudança de posição de reivindicatória para responsável de execução pelas feministas.

Essa conjuntura mostra, entretanto, um abalo nos últimos anos com a retomada de organizações de mulheres e com o ascenso dos movimentos feministas e LGBT frente à expansiva onda conservadora religiosa que ameaça violentamente as conquistas travadas até então. 
O governo é chamado a assumir uma postura ativa, condizente com seu discurso e os planos do passado, mas em grande parte exime-se de aprovar projetos e ações importantes a esses movimentos, acentuando a tensão entre partido, movimentos populares e Estado e ressaltando as diferenças essenciais entre eles.

Nesse sentido, esperamos que uma nova era de lutas e avanços às massas de mulheres latino-americanas edifique-se com a particularidade de um feminismo descolonial e combativo.

\section{REFERÊNCIAS BIBLIOGRÁFICAS}

ALVES, Branca Moreira, PITANGUY, Jacqueline. O que é Feminismo? São Paulo: Ed. Abril cultural; Brasiliense, 1985.

FARIA, Nalu. O feminismo latino-americano e caribenho: perspectivas diante do neoliberalismo. Em: FARIA, Nalu; POULIN, Richard. Desafios do livre mercado para o feminismo. São Paulo: SOF, 2005. .

LUGONES, María; JIMÉNEZ-LUCENA, Isabel; MIGNOLO, Walter (comp). Género y descolonialidad. Buenos Aires: Del Signo, 2008.

MACEDO, Ana Gabriela. Pós-feminismo. Rev. Estud. Fem. Florianópolis, vol.14, no. 3. Set./Dec., 2006.

MATOS, Marlise. Movimento e Teoria Feminista: É possível reconstruir a teoria feminista a partir do Sul Global? Em: Revista de Sociologia e Política, v. 18, n 36: 67-92, jun. 2010, p. 67-92.

NAVÁZ, Liliana Suárez. Colonialismo, Gobernabilidad y Feminismos Poscoloniales. En: Liliana Suárez Navaz y Aída Hernández (editoras): Descolonizando el Feminismo: Teorías y Prácticas desde los Márgenes. Madrid: ed. Cátedra, 2008.

PINTO, Céli Regina Jardim. Feminismo, história e poder. Rev. Sociol. Polit. Curitiba, vol.18, no.36, June 2010.

PINTO, Céli Regina Jardim. Movimentos sociais: espaços privilegiados da mulher enquanto sujeito político. Em: COSTA, Albertina 
de Oliveira; BRUSCHINI, Cristina (orgs). Uma questão de gênero. Rio de Janeiro: Rosa dos Tempos; São Paulo: Fundação Carlos Chagas, 1992. p. $127-151$

RAGO, Margareth. Adeus ao Feminismo? Feminismo e (Pós) Modernidade no Brasil. Cadernos AEL, n. 3/4, 1995/1999.

RODRIGUES, Almira. Práticas Sociais, Modelos de Sociedade e Questões Éticas: Perspectivas Feministas. Em: SUSIN, Luiz Carlos (org). Terra Prometida - Movimento social, engajamento cristão e teologia. Rio de Janeiro: Vozes, 2001. p. 131-142.

SAFFIOTI, Heleieth B. Feminismos e seus frutos no Brasil. In: SADER, Emir (Org.). Movimentos sociais na transição democrática. São Paulo: Cortez, 1986.

SAFFIOTI, Heleieth lara Bongiovani. Gênero, patriarcado, violência. São Paulo: Editora Fundação Perseu Abramo, 2004.

SAFFIOTI, Heleieth lara Bongiovani. A mulher na sociedade de classes: mito e realidade. São Paulo: Expressão Popular, 2013. 